\title{
Transforming Growth Factor- $\beta 1$ as a Common Target Molecule for Development of Cardiovascular Diseases, Renal Insufficiency and Metabolic Syndrome
}

\author{
Ken-ichi Aihara, ${ }^{1}$ Yasumasa Ikeda, ${ }^{2}$ Shusuke Yagi, ${ }^{3}$ Masashi Akaike, ${ }^{3}$ and Toshio Matsumoto ${ }^{1}$ \\ ${ }^{1}$ Department of Medicine and Bioregulatory Sciences, The University of Tokushima, Graduate School of Health Biosciences, \\ 3-18-15 Kuramoto-cho, Tokushima 770-8503, Japan \\ ${ }^{2}$ Department of Pharmacology, The University of Tokushima, Graduate School of Health Biosciences, \\ 3-18-15 Kuramoto-cho, Tokushima 770-8503, Japan \\ ${ }^{3}$ Department of Cardiovascular Medicine, The University of Tokushima, Graduate School of Health Biosciences, \\ 3-18-15 Kuramoto-cho, Tokushima 770-8503, Japan
}

Correspondence should be addressed to Ken-ichi Aihara, aihara@clin.med.tokushima-u.ac.jp

Received 1 October 2010; Accepted 8 December 2010

Academic Editor: David Bishop-Bailey

Copyright (C) 2011 Ken-ichi Aihara et al. This is an open access article distributed under the Creative Commons Attribution License, which permits unrestricted use, distribution, and reproduction in any medium, provided the original work is properly cited.

\begin{abstract}
Transforming growth factor- $\beta 1$ (TGF- $\beta 1$ ) is a polypeptide member of the transforming growth factor $\beta$ superfamily of cytokines. It is a secreted protein that performs many cellular functions including control of cell growth, cell proliferation, cell differentiation and apoptosis. In the cardiovascular system, TGF- $\beta 1$ plays pivotal roles in the pathogenesis of hypertension, restenosis after percutaneous coronary intervention, atherosclerosis, cardiac hypertrophy and heart failure. In addition, TGF- $\beta 1$ has been shown to be increased in adipose tissue of obese subjects with insulin resistance. Furthermore, TGF- $\beta 1$ is a potent initiator of proliferation of renal mesangial cells leading to chronic kidney disease. Some currently available agents can manipulate TGF- $\beta 1$ expression leading to amelioration of cardiovascular diseases. Thus, an understanding of interactions between chronic kidney disease and metabolic syndrome and the development of cardiovascular diseases is an important issue, and attention should be given to TGF- $\beta 1$ as a crucial factor for regulation and modulation of those pathological conditions.
\end{abstract}

\section{Introduction}

Transforming growth factor- $\beta$ (TGF- $\beta$ ) is a polypeptide member of the TGF- $\beta$ superfamily of cytokines. The TGF$\beta$ superfamily consists of TGF- $\beta$, activins, inhibins, growth differentiation factors, and bone morphogenetic proteins (BMPs). The TGF- $\beta$ superfamily proteins share common sequences and motifs to exert their various biological actions, including cell growth, differentiation, proliferation, migration, adhesion, apoptosis, and extracellular matrix (ECM) production (Figure 1) [1-4]. Experimental studies on TGF- $\beta$ signaling pathway manipulation have confirmed crucial roles of TGF- $\beta$ in the process of development and/or regression of malignant tumors, autoimmune diseases, organ fibrotic changes, kidney diseases, and cardiovascular diseases (CVD) [4]. TGF- $\beta$ exists in three known subtypes in humans, TGF- $\beta 1$, TGF- $\beta 2$, and TGF- $\beta 3$. Since TGF$\beta 1$ is present in endothelial cells, vascular smooth muscle cells (VSMCs), myofibroblasts, macrophages, and other hematopoietic cells, it is recognized as the most pivotal TGF- $\beta$ isoform for the cardiovascular system [5]. TGF- $\beta 1$ is synthesized and secreted into the extracellular matrix as an inactive precursor protein consisting of a signal peptide, latency-associated peptide (LAP) domain, and mature TGF$\beta 1$. Activation of TGF- $\beta 1$ is involved in proteolytic cleavage of LAP, and TGF- $\beta 1$ is activated by thrombospondin-1, plasmin, acidic microenvironments, matrix metalloproteinases (MMPs) such as MMP-2 and -9, and $\beta 6$ integrin [5-7]. In VSMCs, angiotensin II (Ang II) enhances TGF- $\beta 1$ mRNA expression by transcriptional and posttranscriptional actions and accelerates its conversion to the biologically active form [8]. 


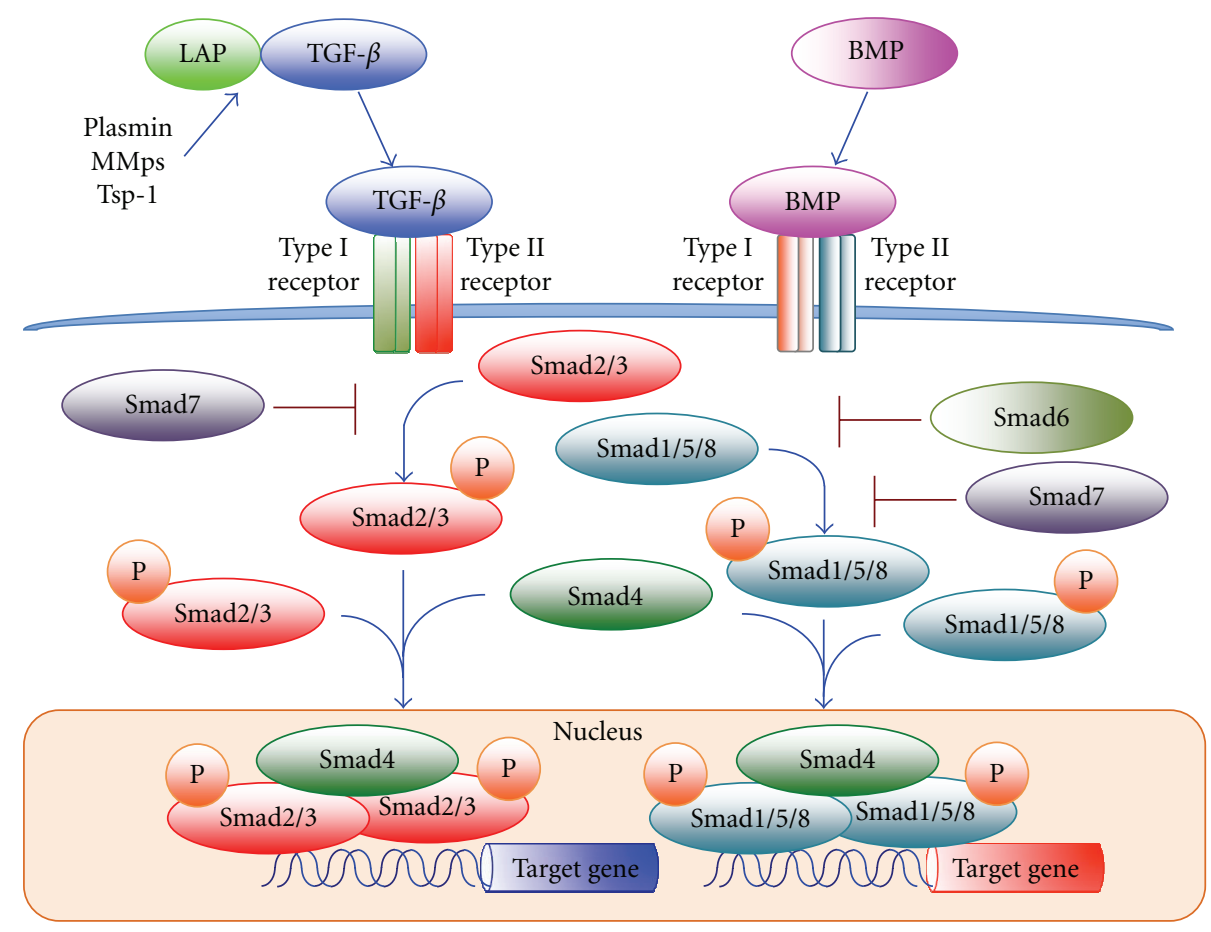

FIGURE 1: Schematic diagram of TGF- $\beta$ superfamily signaling pathway. TGF- $\beta$ is produced as a latent protein that is activated by various factors including plasmin, MMPs, and Tsp-1. Active form of TGF- $\beta$ binds to its receptors and induces Smad $2 / 3$ phosphorylation, and BMPs induce Smad1/5/8 phosporylation. Activated R-Smads, form heteromeric complexes with Smad 4 and regulate the expression of target genes of TGF- $\beta$ such as fibronectin, collagen type I, PAI-1 and MMP-2 in the nucleus. TGF- $\beta$ : transforming growth factor- $\beta$, LAP: latencyassociated peptide, MMPs: metalloproteinases, Tsp-1: thrombospondin-1 and BMP: bone morphogenetic protein.

Previous studies has shown that TGF- $\beta 1$ activation is closely associated with the development of cardiovascular diseases, including hypertension [9], cardiac hypertrophy [10] and cardiac fibrosis [11] leading to heart failure as well as restenosis after coronary intervention [12] and atherosclerosis $[13,14]$. Moreover, TGF- $\beta 1$ is known to induce progression of experimental renal disorders, and it has been shown that there are associations between serum level of TGF- $\beta 1$ and risk factors for progression of clinically relevant renal disorders in humans [15]. Visceral fat obesity with insulin resistance has been considered to play a central role in the development of metabolic syndrome (MetS) leading to an increase in the incidence of cardiovascular events, and recent studies have shown a possible interaction between TGF- $\beta 1$ and visceral fat obesity [16].

There are some elaborate review articles concerning associations between TGF- $\beta 1$ and CVD $[4,17-20]$; however, in this review, we focus on the importance of TGF- $\beta 1$ for, linking the pathologic processes of CVD, renal insufficiency, and MetS.

\section{Mechanism of TGF- $\beta$ Superfamily Signaling Pathway}

TGF- $\beta$ superfamily ligands exert their biological effects via binding to high-affinity cell surface receptors, including type I and type II TGF- $\beta$ superfamily receptors. Seven type I receptors (activin-like kinase (ALK) 1-7) and five type II receptors are known to be present in mammals [21-23]. Type II receptors are constitutively active serine/threonine kinases, with ligand binding resulting in conformational changes that induce recruitment and complex formation with an appropriate type I receptor (ALK1-7) [24], and the type II receptor then phosphorylates the type I receptor in the glycine/serine-rich domain. The activated type I receptors mediate their cellular actions through interaction and phosphorylation of Smad proteins, which are often in complex with other Smads, and act as transcription factors to regulate the expression of various target genes [1,25]. Based on their function, Smads proteins have been classified into three groups: receptor-activated Smads (R-Smads), including Smad1, Smad2, Smad3, Smad5, and Smad8, the comediator Smad Smad4, and inhibitory Smads, Smad6, and Smad7. Smad 2 and Smad 3 are specific mediators of TGF- $\beta$ /activin pathways, whereas Smad1, Smad5, and Smad8 are involved in BMP signaling (Figure 1) $[1,2]$.

\section{TGF- $\beta 1$ and Cardiovascular Diseases}

Since clinical and experimental studies have shown that TGF$\beta 1$ is involved in the development of CVD, it is absolutely imperative to understand the biological actions of TGF- $\beta 1$ in the cardiovascular system. 
3.1. Role of TGF- $\beta 1$ in the Development of Vascular Diseases. In experimental models, targeting disruption of the TGF$\beta 1$ gene prevents neointima hyperplasia and constrictive remodeling after vascular injury such as angioplasty [12, $26,27]$. In diseased vessels such as arteries in patients with atherosclerosis, type I receptor expression is enhanced and TGF- $\beta 1$ stimulates extracellular matrix (ECM) production and can promote early fatty streak lesion formation $[28,29]$. In addition, it has been reported that TGF- $\beta 1$ reduces collagenase production and accelerates the expression of tissue inhibitors of MMPs, resulting in overall inhibition of ECM degradation and leading to excessive matrix accumulation [6, 30]. In addition, TGF- $\beta 1$ can stimulate VSMCs to produce collagen synthesis; however, TGF- $\beta 1$ has been shown to be involved in both positive and negative plaque stabilization [31-33]. TGF- $\beta 1$ also acts as a mediator of vascular fibrosis induced by several cardiovascular stress factors that are involved in CVD, including mechanical stress, angiotensin II (Ang II), high glucose, and advanced glycation products [3436].

3.2. Role of TGF- $\beta 1$ in the Development of Cardiac Diseases. Tissue levels of TGF- $\beta 1$ are markedly increased in the hypertrophic myocardium after cardiac stress loading such as Ang II excess [37, 38]. Furthermore, it has been reported that TGF- $\beta 1$ stimulation alters the program of differentiationrelated gene expression in isolated cardiac myocytes, promoting the synthesis of fetal contractile proteins, characteristic of pressure-overload hypertrophy [39]. Overexpression of TGF$\beta 1$ in transgenic mice results in cardiac hypertrophy that is characterized by both interstitial fibrosis and hypertrophic growth of cardiomyocytes [40]. Local production of TGF- $\beta 1$ in the hypertrophic myocardium and the link between the renin-angiotensin-aldosterone system and TGF- $\beta 1$ signaling pathway are involved in the hypertrophic response. Since it is well known that Ang II enhances TGF- $\beta 1$ expression and TGF- $\beta 1$-Smad signaling pathways, cardiac remodeling, including cardiac hypertrophy, and cardiac fibrosis, through activation of TGF- $\beta 1$ is closely associated with excess of Ang II [4].

On the other hand, Shultz et al. showed that the cardiomyocyte cross sectional area was markedly increased in Ang II-treated wild-type (WT) mice but was unchanged in Ang II-treated TGF- $\beta 1$-deficient mice [10]. We have found that Ang II stimulated cardiac remodeling, including cardiac hypertrophy and left ventricular dysfunction, along with increased expression of TGF- $\beta 1$ in WT mice. We have also found that not only WT mice but also gene-engineered mice such as mice with gene disruption of endothelial nitric oxide synthase (eNOS), androgen receptor, and heparin cofactor II manifested acceleration of Ang II-induced cardiac remodeling with increased expression of TGF- $\beta 1[37,38,41$, 42] (Figure 2).

3.3. Possible Link between TGF- $\beta 1$ and Hypertension. Hypertension is a major cause of the development of cardiovascular events and causes crucial organ damage such as renal sclerosis, stroke, and coronary heart disease. While environmental and lifestyle-related problems including lack of exercise, obesity, and excessive salt intake contribute to the increased incidence of hypertension, approximately $50 \%$ of causes of hypertension are thought to have a genetic background [18]. Recent studies have been suggested that there is a link between increased levels of circulating TGF$\beta 1$ and hypertension [9]. It has been shown that emilin1 , an extracellular matrix protein that is associated with microfibrils of the elastic matrix in the aortic media, modulates TGF- $\beta 1$ availability and is involved in regulation of arterial diameter [43]. Gene disruption of emilin-1 results in increased conversion of pro-TGF- $\beta 1$ to the mature form and a subsequent increase in TGF- $\beta 1$ signaling. The accelerated TGF- $\beta 1$ signaling pathway results in a reduction in arterial lumen diameter with a resultant increase in vascular resistance and hypertension [43]. A possible mechanism is that excessive levels of active TGF- $\beta 1$ cause premature cytostasis of VSMCs and subsequently suppress arterial wall expansion. On the other hand, a study using mice has indicated the possibility that reduced arterial diameter is a secondary consequence of vascular remodeling [44]. These accelerated TGF- $\beta 1$ activation-induced aberrant phenotypes concerning arterial remodeling and elevated blood pressure were abolished by disruption of the TGF- $\beta 1$ gene in mice [10].

3.4. TGF- $\beta$ as a Predictive Biomarker for Cardiovascular Diseases. Previous studies have shown that several components of TGF- $\beta$ superfamily signaling pathways have significance as prognostic markers for CVD. For instance, in patients with coronary artery disease, increased serum levels of TGF$\beta 1$ are significantly associated with extended survival with reduced incidence of coronary events and interventions [45]. In contrast, after angioplasty, there is a greater risk of development of restenosis in patients that have higher levels of TGF- $\beta 1$ in their blood $15 \mathrm{~min}, 24 \mathrm{~h}$, and 2 weeks after the procedure has been performed [46], suggesting that these patients would benefit from additional interventions to prevent restenosis. Further examinations are needed to clarify the significance of serum level of TGF- $\beta 1$ as a biomarker of cardiovascular diseases.

\section{TGF- $\beta 1$ and Progression of Renal Diseases}

TGF- $\beta 1$ is known to induce progression of experimental renal disease [47]. Suthanthiran et al. demonstrated that serum TGF- $\beta 1$ protein levels were positively and significantly associated with plasma renin activity along with elevated systolic and diastolic blood pressure and were predictive of microalbuminuria in African Americans [15]. Connective tissue growth factor (CTGF) expression is stimulated by all TGF- $\beta$ isoforms and is abundant in glomerulosclerosis and other fibrotic disorders [48]. CTGF has been suggested to mediate profibrotic effects of TGF- $\beta 1$ and to facilitate interaction of TGF- $\beta 1$ with its receptor [48]. In addition, TGF- $\beta 1$ is a cytokine known to participate in several processes related to the development of chronic kidney disease (CKD), including tubular degeneration [49]. The major pathogenesis has 


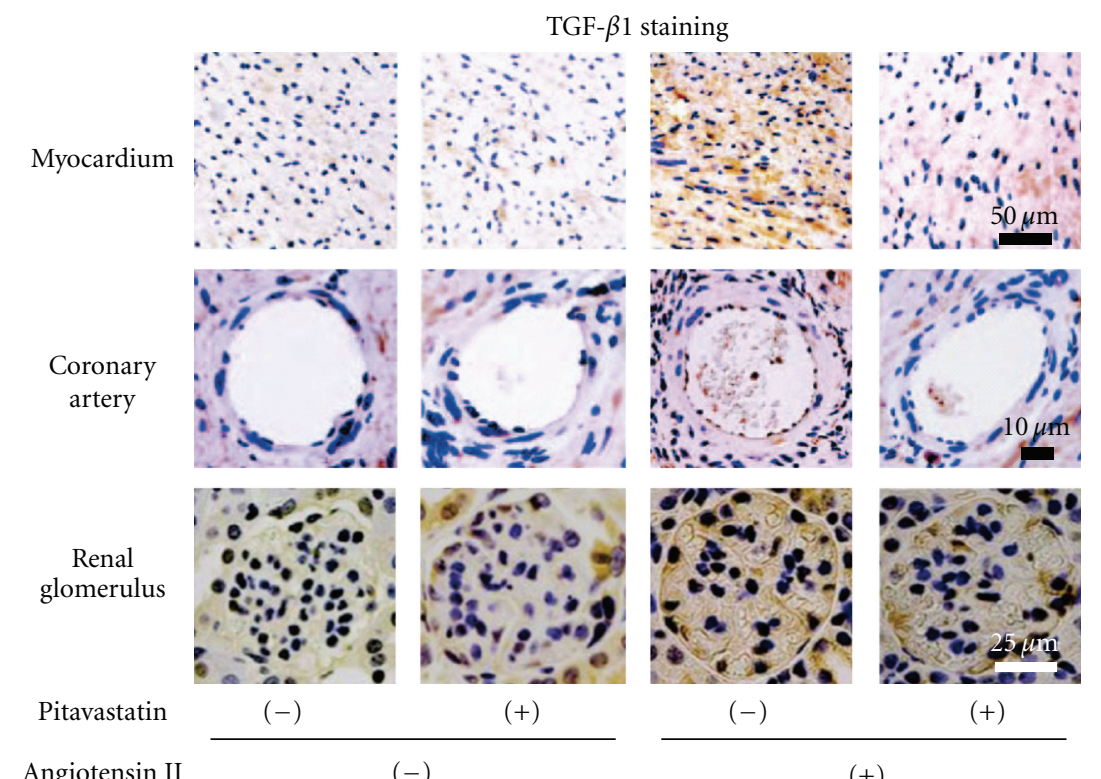

Angiotensin II

$(-)$

$(+)$

FIgURE 2: Cardiorenal immunohistochemistry of TGF- $\beta 1$. TGF- $\beta 1$-stained spots are observed in the myocardium (upper panels) and coronary artery (middle panels) in Ang II-infused wild-type mice (upper and middle panels). Macroscopic renal injury and TGF- $\beta 1$-stained renal glomerulus are found in Ang II-infused mice, especially eNOS ${ }^{-1-}$ mice (lower panels). Pitavastatin treatment attenuates cardiorenal TGF- $\beta 1$ expression in Ang II-infused mice. Modified from the article by Yagi et al. [37].

been thought to be apoptosis and epithelial-to-mesenchymal transition of tubule epithelial cells, which is involved in the fibrotic healing process of the interstitial compartment [49]. On the other hand, in vivo blockade of TGF- $\beta$ action has been shown to reduce CKD-associated tubular damage. Proliferation of injured and hyperplastic podocytes with increased TGF- $\beta 1$ expression has been found in several types of glomerulonephritis [50]; however, pathophysiological roles of TGF- $\beta 1$ in podocyte growth and development of glomerulosclerosis have not been fully elucidated. Since TGF- $\beta$ activates Smads, Ras/extracellular signal-regulated kinase (ERK) and phosphatidyl inositol-3-kinase (PI3K) pathways in podocytes [50], enhancement of the TGF$\beta /$ Smad signaling pathway by hyperplastic podocytes has been thought to lead to mesangial cell matrix overproduction and eventually to podocyte apoptosis and/or detachment, culminating in the development of glomerulosclerosis.

In addition to glomerulonephritis, autosomal dominant polycystic kidney disease (ADPKD), a common inherited renal disease with multiple cysts and interstitial fibrosis in the kidneys, has been noted as an important cause of chronic renal failure. Interestingly, Hassane showed that activation of the TGF- $\beta$-Smad signaling pathway is involved in the progression of ADPKD with increased mRNA levels of TGF- $\beta$ target genes, such as fibronectin, collagen type I, plasminogen activator inhibitor 1 (PAI-1), and MMP-2 [51].

In experimental animal studies, we have found accelerated cardiac remodeling with activation of the TGF- $\beta 1$ Smad 2/3 signaling pathway in Ang II-induced eNOS $/$ +/ and $\mathrm{eNOS}^{-/-}$mice [37]. High-dose Ang II stimulation also markedly increased mortality rate with oliguria in $\mathrm{eNOS}^{-/-}$ mice but not in $\mathrm{eNOS}^{+/+}$mice. In pathological studies, we have found that pitavastatin treatment attenuates the enhanced TGF- $\beta 1$ expression in glomeruli and reduced the high mortality rate in Ang II-treated $\mathrm{eNOS}^{-/-}$mice (Figure 2) [37]. Taken together, these results indicate that activation of the TGF- $\beta 1$-Smad $2 / 3$ signaling pathway is closely involved in the development of cardiorenal disorders.

\section{TGF- $\beta 1$ and Metabolic Syndrome}

Metabolic syndrome is mostly characterized as visceral fat obesity with multiple cardiovascular risk factors, including elevated blood pressure, hyperglycemia, and dyslipidemia. Therefore, an understanding of the molecular mechanism by which visceral obesity is promoted is essential for preventing cardiovascular events in individuals with MetS. In humans, there is a variant of TGF- $\beta 1$, commonly known as Pro 10 , that results from substitution of leucine at codon 10 with proline. This variant has been found in Swedish men and has been found to cause a $4 \%$ increase in BMI, $6 \%$ increase in waist circumference, and a $24 \%$ increase in fasting insulin [52]. Although it has not been determined how the Pro 10 variant form of the TGF- $\beta 1$ protein is linked to visceral adiposity and elevated levels of circulating insulin, there is a possibility that TGF- $\beta 1$ is involved in the insulin resistance with obesity. Since macrophage infiltration into adipose tissue causes insulin resistance $[53,54]$ and since coculture experiments with human adipocytes and macrophages have shown that downstream effectors of TGF- $\beta$ such as PAI1, collagen VI, and phosphorylated Smad were increased 
in both macrophages and adipocytes [55], TGF- $\beta$ has the potential for increasing insulin resistance. In experimental animal studies, Samad et al. reported enhancement of gene and protein expression of TGF- $\beta 1$ in two strains of genetically obese mice (ob/ob and $d b / d b)$ compared with that in lean mice [56] and Raju et al. showed that an obese state increases levels of TGF- $\beta 1$ but not TGF- $\beta 2$ in platelets of Zucker rats, recognized as an experimental model of MetS [57]. Moreover, Sciarretta et al. showed that serum levels of inflammatory markers, including Creactive protein, tumor necrosis factor-alpha and TGF- $\beta$, in hypertensive patients with MetS were significantly higher than those in patients without MetS [16]. Interestingly, Herder et al. showed that elevated serum concentrations of TGF- $\beta 1$ are associated with incident type 2 diabetes and that the association remained stable in multivariate analyses taking into account demographic, anthropometric, metabolic, and lifestyle factors [58]. However, the molecular pathogenesis between increased serum levels of TGF- $\beta 1$ and MetS or type 2 diabetes has not been fully elucidated, and further investigations are needed to clarify this issue.

Since hypertriglycemia is one of the criteria for diagnosis of MetS, treatment with fibrates for dyslipidemia is thought to reduce the development of MetS leading to an increase in cardiovascular events. Nakano et al. demonstrated that bezafibrate directly inhibits hepatic fibrogenic response induced by TGF- $\beta 1$ in vitro. Therefore, the use of bezafibrate has a possibility to be a new therapeutic strategy against nonalcoholic steatohepatitis, hepatic fibrosis, and CVD via attenuation of TGF- $\beta 1$ production [59]. Although consideration should be given to monitoring serum creatinine levels, treatment with fenofibrate, bezafibrate, and gemfibrozil, but not treatment with clofibrate, in patients with elevated triglycerides and low HDL cholesterol resulted in a lower incidence of $\mathrm{CV}$ events without unfavorable effects on atherogenic mortality [60-63].

\section{Pharmacological Manipulation of TGF- $\beta 1$}

Possible links between the TGF- $\beta 1$ signaling pathway and CVD, CKD, and MetS have been noted as mentioned above. Therefore, modulation of the TGF- $\beta 1$ pathway by targetdesigned molecules or existing pharmacological agents might be available therapeutic approach in aberrant expression or signaling activities of TGF- $\beta 1$-related disorders.

6.1. Manipulation of the TGF- $\beta 1$ Signaling Pathway by Specific Inhibitors. Several new properties have been proposed as specific modulators of the TGF- $\beta$ signaling pathway. The secreted exoplasmic domain of the TGF- $\beta$ type II receptor (T $\beta$ RII) inhibits the biological effects of TGF- $\beta 1$ in vitro [64]. Smith et al. demonstrated that TGF- $\beta$ signaling accelerates negative remodeling with adventitial fibrosis and neointima formation in an arterial balloon injury model and that this TGF- $\beta$-mediated effect was inhibited by a soluble TGF- $\beta$ receptor II (T $\beta$ RII) after vascular injury [65]. Kingston et al. performed a randomized trial using a recombinant adenovirus expressing a secreted form of T $\beta$ RII to test the hypothesis that localized inhibition of TGF- $\beta 1$ inhibits luminal loss after angioplasty, and they demonstrated that adenovirus-mediated gene transfer of T $\beta$ RII attenuates vessel stenosis after angioplasty through prevention of constrictive remodeling [66]. Furthermore, small-molecule-specific inhibitors of TGF- $\beta 1$ receptor kinase have been targeted for cancer treatment and experimental investigations for the kidney [67], liver [68], and lung fibrosis [69].

6.2. Manipulation of the TGF- $\beta 1$ Signaling Pathway by Currently Available Agents. Several currently available agents have been shown to act on the TGF- $\beta 1$ signaling pathway. Redondo et al. demonstrated that TGF- $\beta 1$ plays an important role in aspirin-mediated inhibition of cell proliferation via inhibition of VSMC proliferation [70]. They also reported that pioglitazone, a synthetic PPAR- $\gamma$ agonist, subsequently increased the nuclear recruitment of phosphorylated Smad2 via TGF- $\beta 1$ activation leading to VSMC apoptosis [71]. Statins, HMGCoA reductase inhibitors, have been established as efficient agents for reducing coronary plaque instability and cardiovascular death with pleiotropic effects as well as amelioration of aberrant lipid profiles. Moreover, statins have also been shown to be involved in expression of TGF- $\beta 1$ signaling pathways $[37,41,72$, 73]. Porreca et al. showed that pravastatin administration was associated with increased plasma levels of TGF- $\beta 1$ in atherosclerotic patients while increasing both protein synthesis and secretion of TGF- $\beta 1$ in plaque monocytes, and they postulated that activated TGF- $\beta 1$ signaling pathways lead to stabilization of coronary plaque through antiinflammatory actions [72]. Interestingly, we and others have demonstrated that strong statins, including pitavastatin and atorvastatin, reduced tissue expression levels of cardiorenal TGF- $\beta 1$ leading to attenuation of cell proliferation, hypertrophic changes, and fibrotic alterations [37, 41, 73]. Therefore, the detailed mechanism of TGF- $\beta 1$ modulation by statins remains a matter of debate. In addition, inhibitory effects of ACE inhibitors and Rho kinase inhibitors on the TGF- $\beta 1$ signaling pathway have been reported [7476].

Taken together, the results indicate that an understanding of the organ-specific pathological role of TGF- $\beta 1$ and appropriate manipulation of TGF- $\beta 1$ expression and activation should be considered for prevention of cardiorenal diseases.

\section{Conclusions}

An understanding of the complexities of the interplay between the TGF- $\beta 1$ signaling pathway and the development of CVD, CKD, and MetS with insulin resistance are matters of great importance (Figure 3). Based on accumulating evidence concerning TGF- $\beta 1$ signaling pathway and human diseases, appropriate modulation of the biological actions of TGF- $\beta 1$ might be a valuable therapeutic approach in patients with the above-described pathological conditions. 


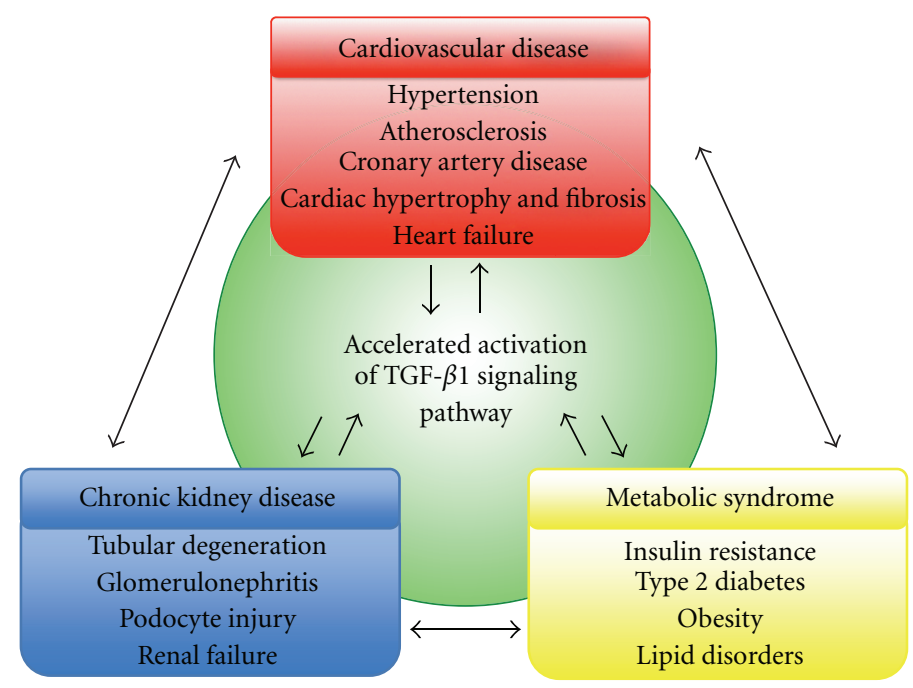

FIGURE 3: Accelerated activation of the TGF- $\beta 1$ signaling pathway causes CKD, MetS, and CVD. Since TGF- $\beta 1$ is a common target molecule and interactive regulator in those pathological conditions, manipulation of the TGF- $\beta 1$ signaling pathway may be a useful approach for amelioration of mortality and morbidity in individuals with cardiovascular risk factors.

\section{Acknowledgments}

This work was supported in part by Grants-in-Aid for Scientific Research from the Ministry of Education, Culture, Sports, Science and Technology of Japan, a grant from the Mitsui Life Social Welfare Foundation, a grant from the Takeda Science Foundation, and a grant for a Study Group on Aseptic Femoral Neck Necrosis from the Ministry of Health, Labour and Welfare of Japan.

\section{References}

[1] J. Massagué, J. Seoane, and D. Wotton, "Smad transcription factors," Genes and Development, vol. 19, no. 23, pp. 27832810, 2005.

[2] D. Javelaud and A. Mauviel, "Mammalian transforming growth factor- $\beta$ s: smad signaling and physio-pathological roles," International Journal of Biochemistry and Cell Biology, vol. 36, no. 7, pp. 1161-1165, 2004.

[3] C. H. Heldin, M. Landström, and A. Moustakas, "Mechanism of TGF- $\beta$ signaling to growth arrest, apoptosis, and epithelialmesenchymal transition," Current Opinion in Cell Biology, vol. 21, no. 2, pp. 166-176, 2009.

[4] M. Ruiz-Ortega, J. Rodríguez-Vita, E. Sanchez-Lopez, G. Carvajal, and J. Egido, "TGF- $\beta$ signaling in vascular fibrosis," Cardiovascular Research, vol. 74, no. 2, pp. 196-206, 2007.

[5] J. P. Annes, J. S. Munger, and D. B. Rifkin, "Making sense of latent TGF $\beta$ activation," Journal of Cell Science, vol. 116, no. 2, pp. 217-224, 2003.

[6] A. Leask and D. J. Abraham, "TGF- $\beta$ signaling and the fibrotic response," FASEB Journal, vol. 18, no. 7, pp. 816-827, 2004.

[7] G. H. Gibbons, R. E. Pratt, and V. J. Dzau, "Vascular smooth muscle cell hypertrophy vs. hyperplasia. Autocrine transforming growth factor- $\beta$ expression determines growth response to angiotensin II," Journal of Clinical Investigation, vol. 90, no. 2, pp. 456-461, 1992.
[8] C. Weigert, K. Brodbeck, K. Klopfer, H. U. Häring, and E. D. Schleicher, "Angiotensin II induces human TGF-beta 1 promoter activation: similarity to hyperglycaemia," Diabetologia, vol. 45, no. 6, pp. 890-898, 2002.

[9] F. Cambien, S. Ricard, A. Troesch et al., "Polymorphisms of the transforming growth factor- $\beta 1$ gene in relation to myocardial infarction and blood pressure: the etude cas-temoin de l'infarctus du myocarde (ECTIM) study," Hypertension, vol. 28, no. 5, pp. 881-887, 1996.

[10] J. E. J. Schultz, S. A. Witt, B. J. Glascock et al., "TGF- $\beta 1$ mediates the hypertrophic cardiomyocyte growth induced by angiotensin II," Journal of Clinical Investigation, vol. 109, no. 6, pp. 787-796, 2002.

[11] A. Leask, "Potential therapeutic targets for cardiac fibrosis: TGF $\beta$, angiotensin, endothelin, CCN2, and PDGF, partners in fibroblast activation," Circulation Research, vol. 106, no. 11, pp. 1675-1680, 2010.

[12] S. Nikol, J. M. Isner, J. G. Pickering, M. Kearney, G. Leclerc, and L. Weir, "Expression of transforming growth factor- $\beta 1$ is increased in human vascular restenosis lesions," Journal of Clinical Investigation, vol. 90, no. 4, pp. 1582-1592, 1992.

[13] K. A. Harradine and R. J. Akhurst, "Mutations of TGF $\beta$ signaling molecules in human disease," Annals of Medicine, vol. 38, no. 6, pp. 403-414, 2006.

[14] A. Bobik, A. Agrotis, P. Kanellakis et al., "Distinct patterns of transforming growth factor- $\beta$ isoform and receptor expression in human atherosclerotic lesions: colocalization implicates TGF- $\beta$ in fibrofatty lesion development," Circulation, vol. 99, no. 22, pp. 2883-2891, 1999.

[15] M. Suthanthiran, L. M. Gerber, J. E. Schwartz et al., "Circulating transforming growth factor- $\beta 1$ levels and the risk for kidney disease in African Americans," Kidney International, vol. 76, no. 1, pp. 72-80, 2009.

[16] S. Sciarretta, A. Ferrucci, G. M. Ciavarella et al., "Markers of inflammation and fibrosis are related to cardiovascular damage in hypertensive patients with metabolic syndrome," American Journal of Hypertension, vol. 20, no. 7, pp. 784-791, 2007. 
[17] P. ten Dijke and H. M. Arthur, "Extracellular control of TGF $\beta$ signalling in vascular development and disease," Nature Reviews Molecular Cell Biology, vol. 8, no. 11, pp. 857-869, 2007.

[18] K. J. Gordon and G. C. Blobe, "Role of transforming growth factor- $\beta$ superfamily signaling pathways in human disease," Biochimica et Biophysica Acta, vol. 1782, no. 4, pp. 197-228, 2008.

[19] M. T. Holderfield and C. C. W. Hughes, "Crosstalk between vascular endothelial growth factor, notch, and transforming growth factor- $\beta$ in vascular morphogenesis," Circulation Research, vol. 102, no. 6, pp. 637-652, 2008.

[20] S. Redondo, C. G. Santos-Gallego, and T. Tejerina, "TGF- $\beta 1$ : a novel target for cardiovascular pharmacology," Cytokine and Growth Factor Reviews, vol. 18, no. 3-4, pp. 279-286, 2007.

[21] C. H. Heldin, K. Miyazono, and P. ten Dijke, "TGF- $\beta$ signalling from cell membrane to nucleus through SMAD proteins," Nature, vol. 390, no. 6659, pp. 465-471, 1997.

[22] Y. Shi and J. Massagué, "Mechanisms of TGF- $\beta$ signaling from cell membrane to the nucleus," Cell, vol. 113, no. 6, pp. 685700, 2003.

[23] B. Schmierer and C. S. Hill, "TGF $\beta-S M A D$ signal transduction: molecular specificity and functional flexibility," Nature Reviews Molecular Cell Biology, vol. 8, no. 12, pp. 970-982, 2007.

[24] D. J. Grainger, "Transforming growth factor $\beta$ and atherosclerosis: so far, so good for the protective cytokine hypothesis," Arteriosclerosis, Thrombosis, and Vascular Biology, vol. 24, no. 3, pp. 399-404, 2004.

[25] R. Derynck, Y. Zhang, and X. H. Feng, "Smads: transcriptional activators of TGF- $\beta$ responses,” Cell, vol. 95 , no. 6, pp. $737-$ 740, 1998.

[26] M. W. Majesky, V. Lindner, D. R. Twardzik, S. M. Schwartz, and M. A. Reidy, "Production of transforming growth factor $\beta$ during repair of arterial injury," Journal of Clinical Investigation, vol. 88, no. 3, pp. 904-910, 1991.

[27] T. Kanzaki, K. Tamura, K. Takahashi et al., "In vivo effect of TGF- $\beta 1$ : enhanced intimal thickening by administration of TGF- $\beta 1$ in rabbit arteries injured with a balloon catheter," Arteriosclerosis, Thrombosis, and Vascular Biology, vol. 15, no. 11, pp. 1951-1957, 1995.

[28] Y. L. Chen, H. W. Wu, and M. J. Jiang, "Transforming growth factor- $\beta 1$ gene and protein expression associated with atherogenesis of cholesterol-fed rabbits," Histology and Histopathology, vol. 15, no. 2, pp. 421-428, 2000.

[29] P. Gourdy, A. Schambourg, C. Filipe et al., "Transforming growth factor activity is a key determinant for the effect of estradiol on fatty streak deposit in hypercholesterolemic mice," Arteriosclerosis, Thrombosis, and Vascular Biology, vol. 27, no. 10, pp. 2214-2221, 2007.

[30] F. Verrecchia and A. Mauviel, "Transforming growth factor$\beta$ signaling through the Smad pathway: role in extracellular matrix gene expression and regulation," Journal of Investigative Dermatology, vol. 118, no. 2, pp. 211-215, 2002.

[31] F. Cipollone, M. Fazia, G. Mincione et al., "Increased expression of transforming growth factor- $\beta 1$ as a stabilizing factor in human atherosclerotic plaques," Stroke, vol. 35, no. 10, pp. 2253-2257, 2004.

[32] G. Draude and R. L. Lorenz, “TGF- $\beta 1$ downregulates CD36 and scavenger receptor A but upregulates LOX-1 in human macrophages," American Journal of Physiology, vol. 278, no. 4, pp. H1042-H1048, 2000.
[33] Z. Mallat, A. Gojova, C. Marchiol-Fournigault et al., "Inhibition of transforming growth factor- $\beta$ signaling accelerates atherosclerosis and induces an unstable plaque phenotype in mice," Circulation Research, vol. 89, no. 10, pp. 930-934, 2001.

[34] M. Ruiz-Ortega, M. Ruperez, V. Esteban, and J. Egido, "Molecular mechanisms of angiotensin II-induced vascular injury," Current Hypertension Reports, vol. 5, no. 1, pp. 73-79, 2003.

[35] J. H. Li, X. R. Huang, H. J. Zhu, R. Johnson, and H. Y. Lan, "Role of TGF- $\beta$ signaling in extracellular matrix production under high glucose conditions," Kidney International, vol. 63, no. 6, pp. 2010-2019, 2003.

[36] J. H. Li, X. R. Huang, H. J. Zhu et al., "Advanced glycation end products activate Smad signaling via TGF-beta-dependent and independent mechanisms: implications for diabetic renal and vascular disease," The FASEB Journal, vol. 18, no. 1, pp. 176178, 2004.

[37] S. Yagi, K. Aihara, Y. Ikeda et al., "Pitavastatin, an HMGCoA reductase inhibitor, exerts eNOS-independent protective actions against angiotensin II-induced cardiovascular remodeling and renal insufficiency," Circulation Research, vol. 102, no. 1, pp. 68-76, 2008.

[38] Y. Ikeda, K. Aihara, T. Sato et al., "Androgen receptor gene knockout male mice exhibit impaired cardiac growth and exacerbation of angiotensin II-induced cardiac fibrosis," Journal of Biological Chemistry, vol. 280, no. 33, pp. 2966129666, 2005.

[39] T. G. Parker, S. E. Packer, and M. D. Schneider, "Peptide growth factors can provoke 'fetal' contractile protein gene expression in rat cardiac myocytes," Journal of Clinical Investigation, vol. 85, no. 2, pp. 507-514, 1990.

[40] S. Rosenkranz, M. Flesch, K. Amann et al., "Alterations of $\beta$-adrenergic signaling and cardiac hypertrophy in transgenic mice overexpressing TGF- $\beta$," American Journal of Physiology, vol. 283, no. 3, pp. H1253-H1262, 2002.

[41] S. Yagi, M. Akaike, K. Aihara et al., "Endothelial nitric oxide synthase-independent protective action of statin against angiotensin ii-induced atrial remodeling via reduced oxidant injury," Hypertension, vol. 55, no. 4, pp. 918-923, 2010.

[42] Y. Sumitomo-Ueda, K. Aihara, T. Ise et al., "Heparin cofactor II protects against angiotensin II-induced cardiac remodeling via attenuation of oxidative stress in mice," Hypertension, vol. 56, no. 3, pp. 430-436, 2010.

[43] L. Zacchigna, C. Vecchione, A. Notte et al., "Emilin1 links TGF- $\beta$ maturation to blood pressure homeostasis," Cell, vol. 124, no. 5, pp. 929-942, 2006.

[44] P. August and M. Suthanthiran, "Transforming growth factor $\beta$ signaling, vascular remodeling, and hypertension," The New England Journal of Medicine, vol. 354, no. 25, pp. 2721-2644, 2006.

[45] H. Tashiro, H. Shimokawa, K. Sadamatu et al., "Prognostic significance of plasma concentrations of transforming growth factor- $\beta$ in patients with coronary artery disease," Coronary Artery Disease, vol. 13, no. 3, pp. 139-143, 2002.

[46] M. Wildgruber, W. Weiss, H. Berger, O. Wolf, H. H. Eckstein, and P. Heider, "Association of circulating transforming growth factor beta, tumor necrosis factor alpha and basic fibroblast growth factor with restenosis after transluminal angioplasty," European Journal of Vascular and Endovascular Surgery, vol. 34, no. 1, pp. 35-43, 2007.

[47] N. Fukuda, Y. Tahira, H. Matsuda, and K. Matsumoto, "Transforming growth factor- $\beta$ as a treatment target in renal diseases," Journal of Nephrology, vol. 22, no. 6, pp. 708-715, 2009. 
[48] Y. Ito, R. Goldschmeding, H. Kasuga et al., "Expression patterns of connective tissue growth factor and of TGF- $\beta$ isoforms during glomerular injury recapitulate glomerulogenesis," American Journal of Physiology, vol. 299, no. 3, pp. F545F558, 2010.

[49] O. García-Sánchez, F. J. López-Hernández, and J. M. LópezNovoa, "An integrative view on the role of TGF- $\beta$ in the progressive tubular deletion associated with chronic kidney disease," Kidney International, vol. 77, pp. 950-955, 2010.

[50] H. S. Lee and C. Y. Song, "Effects of TGF- $\beta$ on podocyte growth and disease progression in proliferative podocytopathies," Kidney and Blood Pressure Research, vol. 33, no. 1, pp. 24-29, 2010.

[51] S. Hassane, W. N. Leonhard, A. van der Wal et al., "Elevated TGF $\beta$-Smad signalling in experimental Pkdl models and human patients with polycystic kidney disease," Journal of Pathology, vol. 222, no. 1, pp. 21-31, 2010.

[52] R. Rosmond, M. Chagnon, C. Bouchard, and P. Björntorp, "Increased abdominal obesity, insulin and glucose levels in nondiabetic subjects with a T29C polymorphism of the transforming growth factor- $\beta$ gene," Hormone Research, vol. 59, no. 4, pp. 191-194, 2003.

[53] H. Xu, G. T. Barnes, Q. Yang et al., "Chronic inflammation in fat plays a crucial role in the development of obesity-related insulin resistance," Journal of Clinical Investigation, vol. 112, no. 12, pp. 1821-1830, 2003.

[54] S. P. Weisberg, D. McCann, M. Desai, M. Rosenbaum, R. L. Leibel, and A. W. Ferrante, "Obesity is associated with macrophage accumulation in adipose tissue," Journal of Clinical Investigation, vol. 112, no. 12, pp. 1796-1808, 2003.

[55] M. Spencer, A. Yao-Borengasser, R. Unal et al., "Adipose tissue macrophages in insulin-resistant subjects are associated with collagen VI and fibrosis and demonstrate alternative activation," American Journal of Physiology, vol. 299, no. 6, pp. E1016-E1027, 2010.

[56] F. Samad, K. Yamamoto, M. Pandey, and D. J. Loskutoff, "Elevated expression of transforming growth factor- $\beta$ in adipose tissue from obese mice," Molecular Medicine, vol. 3, no. 1, pp. 37-48, 1997.

[57] J. Raju, G. Bajaj, J. Chrusch, and R. P. Bird, "Obese state leads to elevated levels of TGF- $\beta$ and COX isoforms in platelets of Zucker rats," Molecular and Cellular Biochemistry, vol. 284, no. 1-2, pp. 19-24, 2006.

[58] C. Herder, A. Zierer, W. Koenig, M. Roden, C. Meisinger, and B. Thorand, "Transforming growth factor- $\beta 1$ and incident type 2 diabetes: results from the MONICA/KORA case-cohort study, 1984-2002," Diabetes Care, vol. 32, no. 10, pp. 19211923, 2009.

[59] S. Nakano, T. Nagasawa, T. Ijiro et al., "Bezafibrate prevents hepatic stellate cell activation and fibrogenesis in a murine steatohepatitis model, and suppresses fibrogenic response induced by transforming growth factor- $\beta 1$ in a cultured stellate cell line," Hepatology Research, vol. 38, no. 10, pp. 1026-1039, 2008.

[60] A. Keech, R J. Simes, P. Barter et al., "Effects of long-term fenofibrate therapy on cardiovascular events in 9795 people with type 2 diabetes mellitus (the FIELD study): randomised controlled trial," The Lancet, vol. 366, pp. 1849-1861, 2005.

[61] A. Tenenbaum, M. Motro, E. Z. Fisman, D. Tanne, V. Boyko, and S. Behar, "Bezafibrate for the secondary prevention of myocardial infarction in patients with metabolic syndrome," Archives of Internal Medicine, vol. 165, no. 10, pp. 1154-1160, 2005.
[62] L. Tenkanen, M. Mänttäri, P. T. Kovanen, H. Virkkunen, and V. Manninen, "Gemfibrozil in the treatment of dyslipidemia: an 18-year mortality follow-up of the Helsinki Heart Study," Archives of Internal Medicine, vol. 166, no. 7, pp. 743-748, 2006.

[63] M. H. Davidson, A. Armani, J. M. McKenney, and T. A. Jacobson, "Safety considerations with fibrate therapy," American Journal of Cardiology, vol. 99, no. 6, pp. S3-S18, 2007.

[64] Y. Shi, J. E. O’Brien Jr., A. Fard, and A. Zalewski, “Transforming growth factor- $\beta 1$ expression and myofibroblast formation during arterial repair," Arteriosclerosis, Thrombosis, and Vascular Biology, vol. 16, no. 10, pp. 1298-1305, 1996.

[65] J. D. Smith, S. R. Bryant, L. L. Couper et al., "Soluble transforming growth factor- $\beta$ type II receptor inhibits negative remodeling, fibroblast transdifferentiation, and intimal lesion formation but not endothelial growth," Circulation Research, vol. 84, no. 10, pp. 1212-1222, 1999.

[66] P. A. Kingston, S. Sinha, A. David, M. G. Castro, P. R. Lowenstein, and A. M. Heagerty, "Adenovirus-mediated gene transfer of a secreted transforming growth factor- $\beta$ type II receptor inhibits luminal loss and constrictive remodeling after coronary angioplasty and enhances adventitial collagen deposition," Circulation, vol. 104, no. 21, pp. 2595-2601, 2001.

[67] E. T. Grygielko, W. M. Martin, C. Tweed et al., "Inhibition of gene markers of fibrosis with a novel inhibitor of transforming growth factor- $\beta$ type I receptor kinase in puromycin-induced nephritis," Journal of Pharmacology and Experimental Therapeutics, vol. 313, no. 3, pp. 943-951, 2005.

[68] A. C. de Gouville, V. Boullay, G. Krysa et al., "Inhibition of TGF- $\beta$ signaling by an ALK5 inhibitor protects rats from dimethylnitrosamine-induced liver fibrosis," British Journal of Pharmacology, vol. 145, no. 2, pp. 166-177, 2005.

[69] P. Bonniaud, P. J. Margetts, M. Kolb et al., "Progressive transforming growth factor $\beta 1$-induced lung fibrosis is blocked by an orally active ALK5 kinase inhibitor," American Journal of Respiratory and Critical Care Medicine, vol. 171, no. 8, pp. 889898, 2005.

[70] S. Redondo, C. G. Santos-Gallego, P. Ganado et al., "Acetylsalicylic acid inhibits cell proliferation by involving transforming growth factor- $\beta$," Circulation, vol. 107, no. 4, pp. 626-629, 2003.

[71] S. Redondo, E. Ruiz, C. G. Santos-Gallego, E. Padilla, and T. Tejerina, "Pioglitazone induces vascular smooth muscle cell apoptosis through a peroxisome proliferator-activated receptor- $\gamma$, transforming growth factor- $\beta 1$, and a Smad2dependent mechanism," Diabetes, vol. 54, no. 3, pp. 811-817, 2005.

[72] E. Porreca, C. Di Febbo, G. Baccante, M. Di Nisio, and F. Cuccurullo, "Increased transforming growth factor-beta circulating levels and production in human monocytes after 3hydroxy-3-methyl-glutaryl-coenzyme a reductase inhibition with pravastatin," Journal of the American College of Cardiology, vol. 39, no. 11, pp. 1752-1757, 2002.

[73] Y. Mizuguchi, A. Miyajima, T. Kosaka, T. Asano, T. Asano, and M. Hayakawa, "Atorvastatin ameliorates renal tissue damage in unilateral ureteral obstruction," Journal of Urology, vol. 172, no. 6 I, pp. 2456-2459, 2004.

[74] J. R. Rumble, R. E. Gilbert, A. Cox, L. Wu, and M. E. Cooper, "Angiotensin converting enzyme inhibition reduces the expression of transforming growth factor- $\beta$ and type IV collagen in diabetic vasculopathy," Journal of Hypertension, vol. 16, no. 11, pp. 1603-1609, 1998. 
[75] Y. Matsumoto, T. Uwatoku, K. Oi et al., "Long-term inhibition of Rho-kinase suppresses neointimal formation after stent implantation in porcine coronary arteries: involvement of multiple mechanisms," Arteriosclerosis, Thrombosis, and Vascular Biology, vol. 24, no. 1, pp. 181-186, 2004.

[76] H. Peng, O. A. Carretero, N. Vuljaj et al., "Angiotensinconverting enzyme inhibitors: a new mechanism of action," Circulation, vol. 112, no. 16, pp. 2436-2445, 2005. 


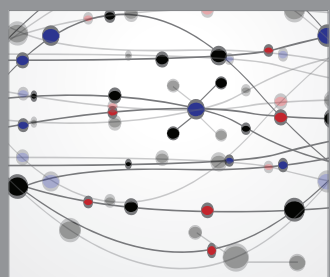

The Scientific World Journal
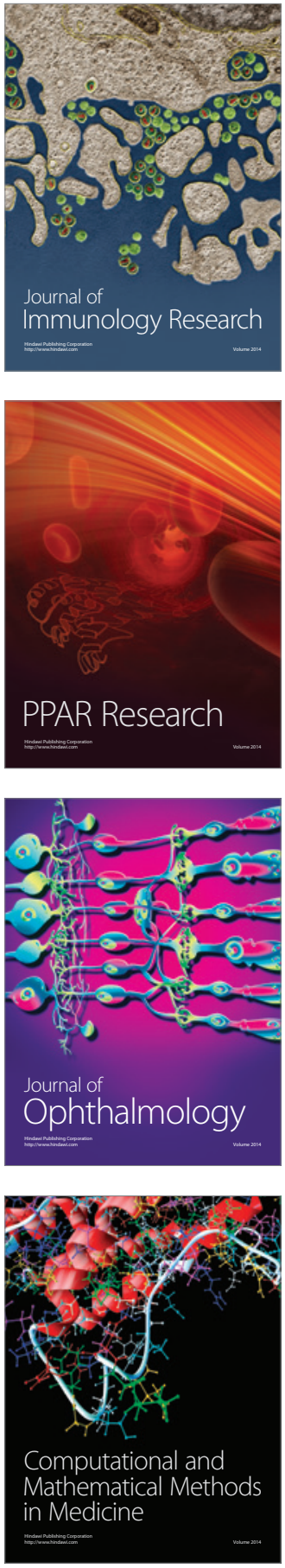

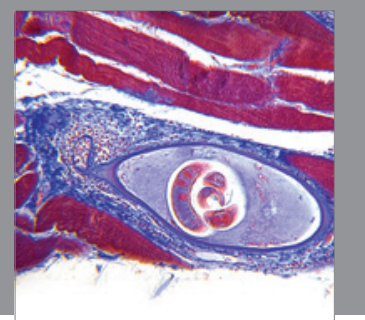

Gastroenterology

Research and Practice
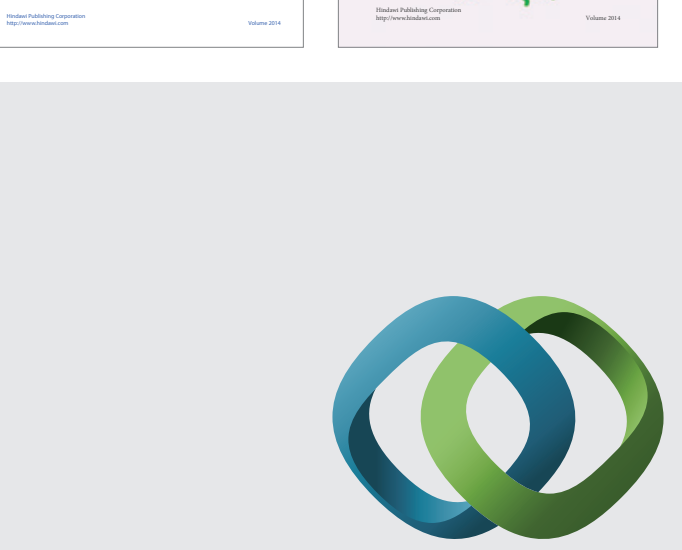

\section{Hindawi}

Submit your manuscripts at

http://www.hindawi.com
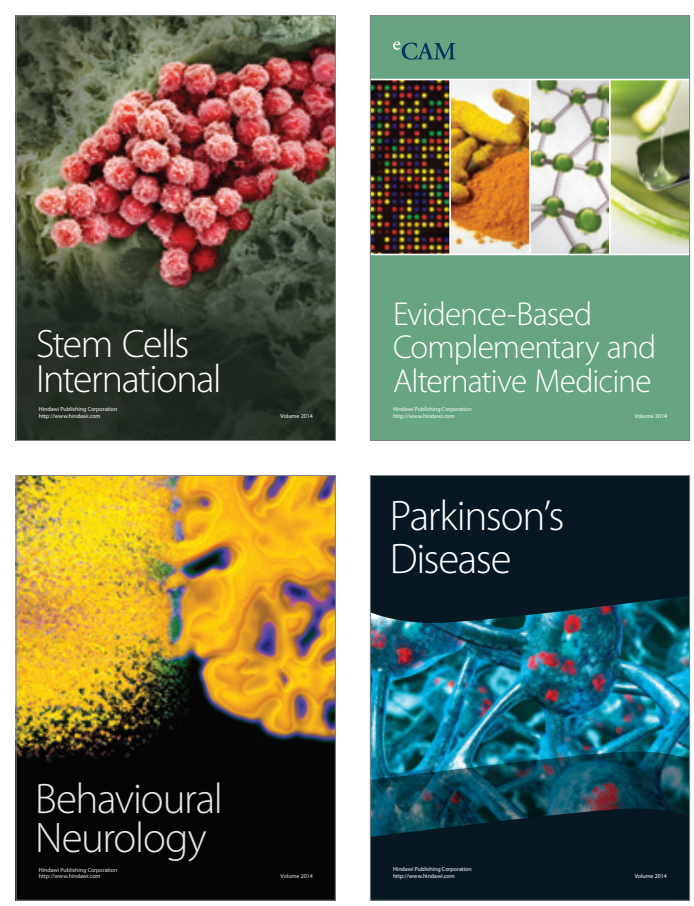

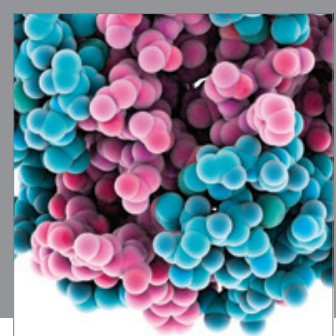

Journal of
Diabetes Research

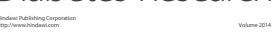

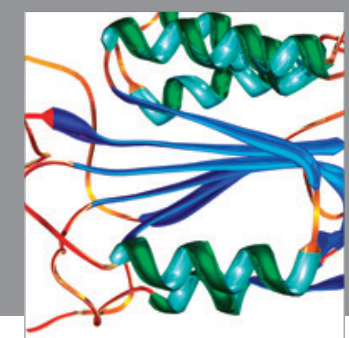

Disease Markers
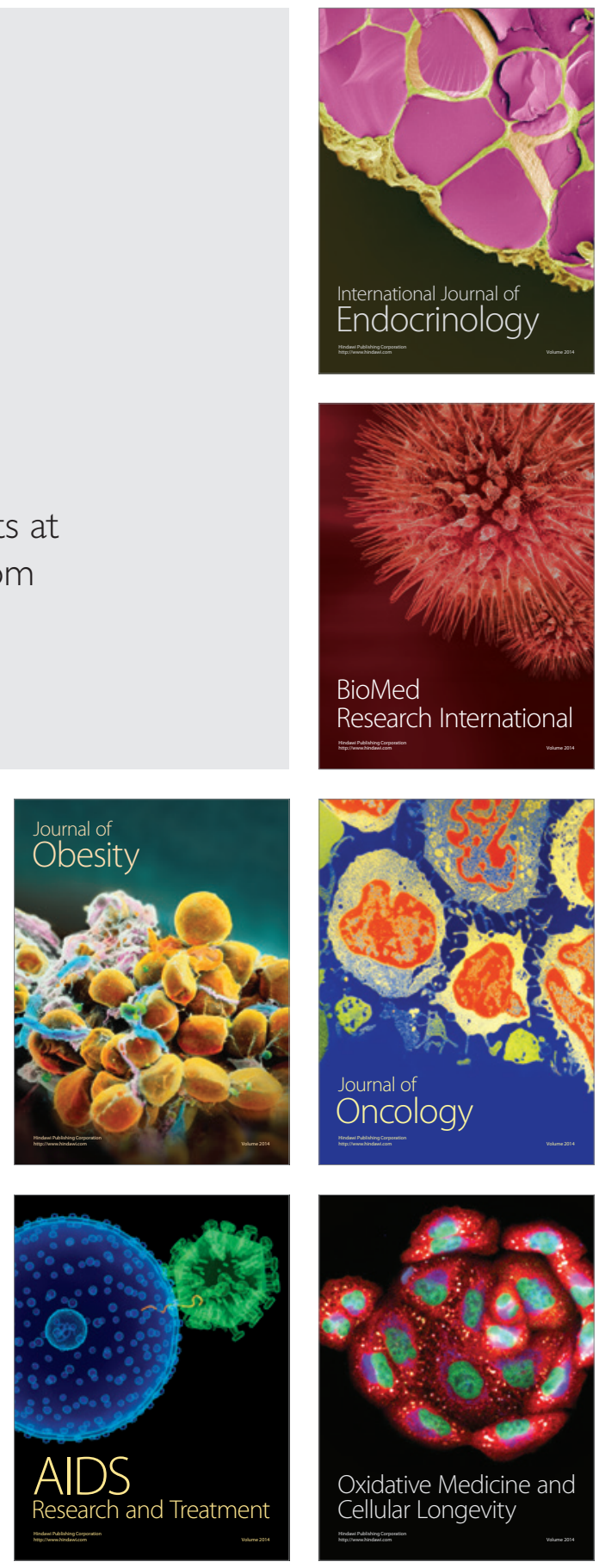